\title{
Organ of hearing and balance in peri- and postmenopausal women. Effects of hormone replacement therapy on hearing and balance in peri- and post-menopausal women: The current state of knowledge
}

\author{
Krystyna Orendorz-Frączkowska ${ }^{A-F}$, Hanna Temporale ${ }^{A-D, F}$ \\ Department and Clinic of Otolaryngology Head and Neck Surgery, Wroclaw Medical University, Poland \\ A - research concept and design; B - collection and/or assembly of data; C - data analysis and interpretation; \\ $D$ - writing the article; $E$ - critical revision of the article; $F$ - final approval of the article
}

Address for correspondence

Hanna Temporale

E-mail: hanna.temporale@gmail.com

Funding sources

None declared

Conflict of interest

None declared

Received on August 1, 2019

Reviewed on 0ctober 14, 2019

Accepted on May 1, 2020

Published online on June 26, 2020

\begin{abstract}
Sensory-neural hearing loss in people over 50 - senile deafness - is currently an increasing problem due to the growing proportion of the elderly people in the population. We can find a number of worldwide publications on hearing loss and dizziness in peri-menopausal women, but the data is inconsistent. Reports describing the influence of sex hormones on the ear and its aging are similarly controversial. This review attempts to summarize the current state of knowledge regarding hearing and balance in women during menopause, based on recent studies in this field. It describes the possible causes of hearing and balance impairment in post-menopausal women other than the mere physiological aging of the ear. The review concludes that impairment of hearing and balance is significantly related to osteoporosis, which results from estrogen deficiency during menopause. It also presents the results of studies on the impact of hormone replacement therapy (HRT) and of particular hormonal components of HRT on hearing and balance. The European population is aging, so accurate knowledge about the effects of HRT on hearing and balance is crucial in the context of improving the quality of life of elderly women through appropriate qualification for hormone substitution therapy. Further detailed and extensive study is necessary to verify the impact of sex hormones on hearing in post-menopausal women, taking into account the type of HRT used, serum hormone levels and the presence or absence of osteoporosis.
\end{abstract}

Key words: dizziness, imbalance, benign paroxysmal positional vertigo, menopause, hearing loss

Cite as

Orendorz-Frączkowska K, Temporale H. Organ of hearing and balance in peri- and postmenopausal women. Effects of hormone replacement therapy on hearing and balance in peri- and post-menopausal women: The current state of knowledge. Adv Clin Exp Med. 2020;29(6):751-755. doi:10.17219/acem/121935

D0I

10.17219/acem/121935

Copyright

Copyright by Author(s)

This is an article distributed under the terms of the

Creative Commons Attribution 3.0 Unported (CC BY 3.0)

(https://creativecommons.org/licenses/by/3.0/) 
The period of menopause is associated with the occurrence of many disorders related to deficiencies of female sex hormones caused by the physiological loss of ovarian activity. Estrogens play a significant role in the function of many organs and processes. ${ }^{1-5}$ It is currently known that they are also found in the human brain and are involved in central auditory processes. ${ }^{1}$

Menopause occurs on average around the age of 50 (between 45 and 55 years of age). The climacteric syndrome and the intensity of its symptoms is commonly evaluated according to the Blatt-Kupperman menopausal index. ${ }^{2,8}$ The syndrome is present in $78-92 \%$ of women, according to different sources, mostly affecting working women and substantially impairing their quality of life. ${ }^{2}$ Vasomotor disorders associated with the release of the luteinizing hormone into the bloodstream and the accompanying low estradiol and progestagen levels are considered the underlying mechanism of climacteric symptoms - vasomotor ones in particular. ${ }^{6}$ Disorders of catecholamine metabolism, especially dopamine and norepinephrine, may be responsible for vertigo, postural instability and emotional volatility, because these neurotransmitters affect the hypothalamicpituitary axis and have a major impact on mood and physical activity. ${ }^{7}$ Psychological mechanisms associated with a woman's personality type and her socioeconomic status have also been shown to be important factors modifying the severity of climacteric symptoms: Women with a strong personalities and high socioeconomic status deal much better with menopausal symptoms, including dizziness. ${ }^{7}$

Hormone replacement therapy (HRT) was first introduced in 1960s with the aim of reducing unpleasant climacteric symptoms and preventing the occurrence of osteoporosis and cardiovascular events associated with the deficiency of female sex hormones. ${ }^{3,8,9}$ It has been used as a monotherapy, by supplementing estrogens (17-estradiol, estriol); in combinations of estrogens with gestagens (progesterone, 17-hydroxyprogesterone, 19-nortestosterone); or by administering tibolone, a synthetic steroid precursor. ${ }^{8}$ Meta-analyses from numerous studies have assessed the risks and benefits of short- and long-term use of HRT, including reductions in the prevalence of osteoporosis or cardiovascular events, and improvements in cognitive functions. ${ }^{8,9}$

The association of hearing impairment and menopause is not as clear as dizziness and menopause; moreover, hearing loss is not included in the menopausal syndrome. For many years, scientists have not considered reasons for the deterioration of hearing in post-menopausal women other than the physiological aging of the hearing organ. This was due to the fact that in many menopausal women, despite a subjective impression of deteriorating hearing, threshold tone audiometry showed no greater reduction in hearing sensitivity than what was appropriate for their age. ${ }^{1}$ However, Trott et al. showed that in menopausal women with a normal hearing threshold, the latencies in auditory brainstem potentials (ABR) are significantly longer and their hearing in noisy surroundings is significantly worse compared to a control group of menstruating women of a similar age. This, according to the authors, indicates central hearing deficits in women with sex hormone deficiencies who hear worse despite normal results in audiometric tests. ${ }^{1}$ On the other hand, in the opinion of other researchers who have reported sensory-neural hearing loss in some post-menopausal women, the loss results from dysfunction of the cochlea associated with osteoporosis. ${ }^{5,10-12}$

The results of studies on the impact of HRT on hearing are ambiguous. Some authors have shown that HRT has a beneficial effect on women's hearing in comparison with women who do not use it.,12,13 Chen et al. assessed the risk of sudden sensory-neural hearing loss (SSNHL) in 13,112 women aged 45-79 using HRT and in 39,336 women not taking HRT. They reported no significant difference in the number of cases with SSNHL in the group that used HRT compared to the control group. On this basis, they concluded that HRT is not associated with a greater risk of SSNHL than in menopausal women who do not use HRT. ${ }^{14}$ The same authors analyzed the occurrence of tinnitus in a group of 13,920 women using HRT and 41,760 women not using HRT. They reported a significantly lower number of tinnitus cases in the group using HRT, concluding that HRT may potentially be beneficial in the prevention of tinnitus in women during menopause. ${ }^{15}$ However, this report is in contradiction to the observations by Curhan et al., who found a higher risk of hearing loss in post-menopausal women using HRT, which increased significantly with the length of time it is used. ${ }^{13}$ According to Lee et al., the risk of tinnitus rises with HRT. ${ }^{16}$

Some studies have presented the influence of particular hormones that are components of HRT on the functioning of the hearing organ. Guimaraes et al. noted a negative effect of progesterone on inner ear function and the central auditory pathways; they also found that estrogen monotherapy has no protective effect against the aging of the hearing organ. ${ }^{17}$ Price et al. described the side effects of combined estrogen-progesterone HRT on women's hearing in the form of a significant reduction of amplitudes in otoacoustic emission tests after 2 months of this therapy. ${ }^{18}$ In 2019, Williamson et al. on the one hand confirmed the negative effect of progesterone on evoked auditory brainstem potentials; on the other hand, by analyzing the results of auditory brainstem response (ABR) and gapsin-noise (GIN) tests, they hypothesized that progesterone has a protective effect on the central auditory processing mechanisms. ${ }^{19}$ In addition, by observing the expression of IGF-1R and Fox03 genes, they pointed to the positive effect of estrogens on delaying cochlear aging at the cellular level. ${ }^{19}$

As a result of the fact that some post-menopausal women are diagnosed with both peripheral and central hearing loss, questions about the pathomechanism 
of this phenomenon arise. ${ }^{4,5,11,12,20-22}$ Due to the known association between bone demineralization and estrogen deficiency, osteoporosis has been considered as a potential cause. Progressive changes in the bone structure can potentially lead to the degeneration of the ossicles with decreases in their mass and reductions in the density of the bony cochlear capsule. Changes in the bone structure may also cause disturbances in sound transmission to the cochlea. ${ }^{10,11,21-23}$ Mendy et al. examined more than 8,000 women over 40 years of age and found a significant relationship between the severity of osteoporosis and the occurrence of sensory-neural hearing loss. ${ }^{22}$ These results have been confirmed by other authors. ${ }^{5,10,11,16,20-22,24}$ Kim et al. analyzed hearing test results in 68,241 people over 50 years of age with osteoporosis, and they showed an additional high risk of SSNHL in women with osteoporosis, significantly higher than in the control group of individuals not burdened with osteoporosis. ${ }^{20}$

Table 1 summarizes the latest reports showing the results of hearing tests in peri-menopausal women. These works are mainly focused on evaluating hearing impairment and tinnitus risk factors such as osteoporosis and HRT.

Although dizziness is one of the most common symptoms occurring during the climacteric period, its pathomechanisms are not well understood. Rzewnicki et al. showed vestibular dysfunction of mainly a central character (sporadically peripheral) in post-menopausal women who did not use HRT. ${ }^{25}$ Similar results were previously reported by Orendorz-Frączkowska et al. ${ }^{2}$ In addition, posturographic studies have shown worse central coordination in the area of the vestibular system, especially after excluding visual control in menopausal women additionally reporting dizziness. In the control group of women using HRT, the postural control parameters were significantly better than in the group that did not use it. ${ }^{2}$ Mendy et al. also registered balance impairment in posturographic tests of a group of 8,863 women over 40 years of age. It appeared predominantly in women over 65 years and was significantly associated with decreases in bone mineral density (BMD). ${ }^{22}$ The latest research by Berk et al. confirmed these observations. In their opinion, not only osteoporosis but also balance impairment causing an increasing incidence of falls is an important risk factor for bone fractures at this age. ${ }^{5}$

Benign paroxysmal positional vertigo (BPPV) is one of the causes of dizziness during menopause. Dizziness associated with BPPV increases with age regardless of gender; however, it occurs significantly more often in women during menopause. That is why investigators are interested in researching the causes of the increased prevalence of BPPV in women in this period. ${ }^{26-30}$ So far, Owada et al. are the only researches to report BPPV in a similarly high percentage of women with dizziness and climacteric

Table 1. Organ of hearing and balance in peri- and postmenopausal women - current reports

\begin{tabular}{|c|c|c|c|}
\hline Authors & Published & Aim of the study & Conclusion \\
\hline Kahveci et al. [10] & $\begin{array}{l}\text { Clin Otolaryngol. } \\
2014\end{array}$ & $\begin{array}{c}\text { Correlation between osteoporosis and } \\
\text { hearing impairment }\end{array}$ & $\begin{array}{c}\text { Osteoporosis is associated with an increased } \\
\text { risk of sensory-neural hearing loss with cochlear } \\
\text { dysfunction. }\end{array}$ \\
\hline Mendy et al. [22] & $\begin{array}{l}\text { Ann Epidemiol. } \\
2014\end{array}$ & $\begin{array}{l}\text { Correlation between osteoporosis and } \\
\text { hearing and balance impairment }\end{array}$ & $\begin{array}{l}\text { Osteoporosis can cause hearing and balance } \\
\text { impairment in elderly women. }\end{array}$ \\
\hline Kim et al. [20] & $\begin{array}{l}\text { Auris Nasus Larynx. } \\
2016\end{array}$ & $\begin{array}{c}\text { Correlation between osteoporosis and } \\
\text { hearing impairment }\end{array}$ & Osteoporosis can cause hearing impairment. \\
\hline Jung et al. [23] & $\begin{array}{l}\text { Clin Exp Otorhinolaryngol. } \\
2016\end{array}$ & $\begin{array}{l}\text { Correlation between osteoporosis and } \\
\text { hearing after menopausal period }\end{array}$ & Osteoporosis can cause hearing impairment. \\
\hline Upala et al. [24] & $\begin{array}{l}\text { Braz J Otorhinolaryngol. } \\
2017\end{array}$ & $\begin{array}{l}\text { Correlation between osteoporosis and } \\
\text { hearing impairment - meta-analysis }\end{array}$ & $\begin{array}{c}\text { Osteoporosis is one of the risk factors of hearing } \\
\text { impairment. }\end{array}$ \\
\hline Kshithi et al. [11] & $\begin{array}{l}\text { Am J Otolaryngol. } \\
2018\end{array}$ & $\begin{array}{l}\text { Hearing impairment in post-menopausal } \\
\text { women in correlation with osteoporosis }\end{array}$ & $\begin{array}{c}\text { Osteoporosis is associated with an increased } \\
\text { risk of sensory-neural hearing loss with cochlear } \\
\text { dysfunction. }\end{array}$ \\
\hline Lee et al. [16] & $\begin{array}{l}\text { BMJ Open. } \\
2018\end{array}$ & $\begin{array}{l}\text { Correlation between severity } \\
\text { of osteoporosis and hearing impairment }\end{array}$ & $\begin{array}{l}\text { The risk of hearing impairment increases with } \\
\text { the severity of osteoporosis. }\end{array}$ \\
\hline Chen et al. [15] & $\begin{array}{l}\text { Oncotarget. } \\
2018\end{array}$ & Risk of tinnitus in women using HRT & $\begin{array}{l}\text { HRT gives the potential benefit of preventing } \\
\text { tinnitus. }\end{array}$ \\
\hline Trott et al. [1] & $\begin{array}{l}\text { J Am Acad Audiol. } \\
2019\end{array}$ & $\begin{array}{l}\text { Sex hormones and hearing. Central } \\
\text { auditory processing in women }\end{array}$ & $\begin{array}{l}\text { Central auditory processing impairment can occur } \\
\text { in post-menopausal women with normal hearing. }\end{array}$ \\
\hline Chen et al. [14] & $\begin{array}{l}\text { Menopause. } \\
2019\end{array}$ & $\begin{array}{l}\text { Risk of sudden sensory-neural hearing loss } \\
\text { in correlation with HRT }\end{array}$ & $\begin{array}{c}\text { There was no increase in the risk of sudden sensory- } \\
\text { neural hearing loss when using HRT. }\end{array}$ \\
\hline Wiliamson et al. [19] & $\begin{array}{l}\text { Aging Cell. } \\
2019\end{array}$ & $\begin{array}{l}\text { Correlation between HRT and hearing } \\
\text { impairment }\end{array}$ & $\begin{array}{l}\text { Neuroprotective effect of HRT in auditory brainstem } \\
\text { evoked potentials. }\end{array}$ \\
\hline Yoo et al. [21] & $\begin{array}{l}\text { Braz J Otorhinolaryngol. } \\
2019\end{array}$ & $\begin{array}{c}\text { Correlation between osteoporosis and } \\
\text { hearing impairment }\end{array}$ & $\begin{array}{l}\text { Significantly worse hearing thresholds } \\
\text { in the presence of osteoporosis. }\end{array}$ \\
\hline
\end{tabular}

HRT - hormone replacement therapy. 
symptoms (56.2\%) as in an age-matched group with dizziness but without menopausal symptoms (52.9\%). ${ }^{31}$

To investigate the correlation between dizziness and menopause, Yang et al. experimentally induced menopause in mice by performing bilateral ovariectomies; they noted significant balance behavioral deficits in those animals, showing that estrogen deficiency compromises otoconia maintenance and anchoring by reducing the expression of the otoconial component/anchoring proteins. ${ }^{32}$ Perhaps this could explain the increase in the prevalence of BPPV in women after the cessation of ovarian activity. A number of reports show a correlation between lower BMD and a higher risk of BPPV. ${ }^{5,22,26-30}$ Studies by Zhai et al. and Zhang et al. have proven that by improving BMD, the use of HRT significantly reduces the incidence of BPPV in women compared to the control group of women not using HRT (17.6\% vs 61.5\%). ${ }^{26,27}$ These researchers believe that HRT may be worth considering as a preventive treatment in recurrent BPPV in postmenopausal women. ${ }^{26,27,30}$

Owada et al. have found that women aged 40-59 with climacteric symptoms and dizziness suffer from Meniere's disease $(17.8 \%)$ significantly more often than women of the same age presenting only dizziness (9.7\%). The authors perceived psychological factors as the reason for this difference. ${ }^{31}$ The substantial contribution of psychological factors to the pathomechanism of vertigo has been presented by Terauchi et al., who noted anxiety disorders in $35.7 \%$ of their study group of women with dizziness during menopause, indicating that anxiety treatment may reduce dizziness. ${ }^{7}$

Owada and Suzuki investigated the relationship between the presence of vasomotor symptoms and the occurrence of non-systemic recurrent dizziness during menopause. ${ }^{6}$ Women without vasomotor symptoms during the twomonth observation presented a significantly higher frequency of recurrences of dizziness than women who had these symptoms, which would suggest a lack of connection between them. However, after the women with menopausal symptoms began using HRT, the dizziness disappeared much faster than in women who did not use HRT. ${ }^{6}$

Due to the aging of European society, it is important to prevent and solve problems of the older population. Hearing loss, tinnitus and dizziness have a significantly strong impact on the patients' quality of life, including their family and professional relationships. Reliable knowledge about hearing and balance disorders in post-menopausal women offers a physician the chance to prevent or at least considerably delay these dysfunctions by adjusting HRT or osteoporosis treatment. At the same time, it is important to eliminate the negative impact of HRT on the functioning of the organ of hearing and balance. These data may provide the basis to specify new indications and contraindications for the use of HRT in the future or to determine the need for audiological monitoring in peri-menopausal women. In addition, evidence of the negative impact of HRT on hearing and balance should complement the list of side effects of HRT, along with the risks of breast cancer, venous thromboembolism or dementia, so that doctors and patients can make informed decisions about replacement therapy, bearing in mind the risk of hearing impairment. This is especially important for women with hearing impairment diagnosed before hormonal treatment.

Here is a summary of the current state of knowledge regarding hearing and balance in women during menopause, based on a review of current research in this field:

1. Both peripheral and central hearing deteriorate in the peri-menopausal period.

2. Vertigo and dizziness are very common, and their causes are complex. One of the most common causes of dizziness during menopause is BPPV, but Meniere's disease is also more prevalent than in a comparable age group without menopausal symptoms.

3. Impairment of hearing and balance are significantly related to osteoporosis (decreased BMD), which results from the deficiency of estrogen during menopause.

4. Psychogenic factors such as anxiety and depression play an important role in the severity of dizziness.

5. Researchers' assessments of the impact of HRT on hearing organ functionality, including tinnitus as well as vertigo and dizziness, are varied. Some authors point out improvements in hearing and reductions in balance disorders during its use; others suggest the possibility of HRT causing damage to these senses.

\section{ORCID iDs}

Krystyna Orendorz-Frączkowska

(1) https://orcid.org/0000-0002-9257-5156

Hanna Temporale (10) https://orcid.org/0000-0001-7054-5098

\section{References}

1. Trott S, Cline T, Weihing J, Beshear D, Bush M, Shinn J. Hormones and hearing: Central auditory processing in women. J Am Acad Audiol. 2019;30(6):493-501.

2. Orendorz-Frączkowska K, Pośpiech L, Gawron W, JędrzejukD. Zawroty głowy u kobiet w okresie menopauzy. Otolaryngol Pol. 2004;58(2): 359-364.

3. Greene J. HRT has an uncertainty problem. Does compounding make it worse? Manag Care. 2019;28(2):32-35.

4. Hederstierna C, Hultcrantz M, Collins A. Hearing in women at menopause: Prevalence of hearing loss, audiometric configuration and relation to hormone replacement therapy. Acta Otolaryngol. 2017; 127(2):149-155.

5. Berk E, Koca TT, Guzelsov SS, Nacitarhan V, Demirel A. Evaluation of the relationship between osteoporosis, balance, fall risk and audiological parameters. Clin Rheumatol. 2019;38(11):3261-3268. doi:10. 1007/s10067-019-04655-6

6. Owada S, Suzuki M. The relationship between vasomotor symptoms and menopause-associated dizziness. Acta Otolaryngol. 2014;134(2): 146-150. doi:10.3109/00016489.2013.841991

7. Terauchi M, Odai T, Hirose A, et al. Dizziness in peri- and post-menopausal women is associated with anxiety: A cross-sectional study. BioPsychSocial Med. 2018;12(1). doi:10.1186/s13030-018-0140-1

8. Lobo RA. Hormone-replacement therapy: Current thinking. Nat Rev Endocrinol. 2017;13(4):220-231.

9. Marjoribanks J, Farquhar C, Roberts H, Lethaby A, Lee J. Longterm hormone therapy for peri-menopausal and post-menopausal women. Cochrane Database Syst Rev. 2017;1(1):CD004143. doi:10.1002/ 1465185. CD004143.pub5 
10. Kahveci OK, Demirdal US, Yucedag F, Cerci U. Patients with osteoporosis have higher incidence of sensory-neural hearing loss. Clin Otolaryngol. 2014;39(3):145-149.

11. Kshithi K, Vijendra Shenoy S, Panduranga Kamath M, et al. Audiological profiling in post-menopausal women with osteoporosis. Am J Otolaryngol. 2018;39(3):271-276.

12. Kosus N, Kosus A, Turhan N, Kurtaran H. Hearing levels in menopausal women and the effect of tibolone on audiological functions. J Obstet Gynaecol. 2012;32(3):294-297.

13. Curhan SG, Eliassen AH, Eavey RD, Wang M, Lin BM, Curhan GC. Menopause and post-menopausal hormone therapy and risk of hearing loss. Menopause. 2017;24(9):1049-1056. doi:10.1097/GME.0000000 000000878

14. Chen PJ, Chung $\mathrm{CH}$, Chien WC, Chen HC. Hormone therapy is not associated with the risk of sudden sensory-neural hearing loss in post-menopausal women: A 10-year nationwide population-based study. Menopause. 2019;26(8):892-898. doi:10.1097/GME.0000000000 001323

15. Chen HC, Chung $\mathrm{CH}$, Chen VCF, Wang YC, Chien WC. Hormone replacement therapy decreases the risk of tinnitus in menopausal women: A nationwide study. Oncotarget. 2018;9(28):19807-19816.

16. Lee SS, Han KD, Joo YH. Association of perceived tinnitus with duration of hormone replacement therapy in Korean post-menopausal women: A cross-sectional study. BMJOpen. 2017;7(7):e013736. doi:10. 1136/bmjopen-2016-0137336

17. Guimaraes P, Fristina $S$, Mapes F. Progestin negatively affects hearing in aged women. Proc Natl Acad Sci U S A. 2006;103(38):14246-14249.

18. Price K, Zhu X, Guimares P. Hormone replacement therapy diminishes hearing in peri-menopausal mice. Hear Res. 2019;252(1-2):29-36.

19. Williamson TT, Ding B, Zhu X, Frisina RD. Hormone replacement ther apy attenuates hearing loss: Mechanisms involving estrogen and the IGF-1 pathway. Aging Cell. 2019;18:e12939. doi:10.1111/acel.12939

20. Kim JY, Lee SB, Lee CH, Kim HM. Hearing loss in post-menopausal women with low bone mineral density. Auris Nasus Larynx. 2016;43(2): $155-160$.

21. Yoo Jl, Park KS, Seo SH, Park HW. Osteoporosis and hearing loss: Findings from the Korea National Health and Nutrition Examination Survey 2009-1011. Braz J Otorhinolaryngol. 2019;S1808-8694(18)30488-9. doi:10.1016/j. bjorl.2018.12
22. Mendy A, Vieira ER, Albatineh AN, Lowry D, Gasana J. Low bone mineral density is associated with balance and hearing impairment. Ann Epidemiol. 2014;24(1):58-62. doi:10.1016/j. annepidem.2013.10.012

23. Jung DJ, Cho HH, Lee KY. Association of bone mineral density with hearing impairment in post-menopausal women in Korea. Clin Exp Otorhinolaryngol. 2016;9(4):319-325.

24. Upala S, Rattanawong P, Vutthikraivit W, Sanguankeo A. Significant association between osteoporosis and hearing loss: A systematic review and meta-analysis. Braz J Otorhinolaryngol. 2017;83(6): 646-652.

25. Rzewnicki I,KnappP, Kluz-Kowal AB, Kuryliszyn-Moskal A, TerlikowskiR. Activity of vestibular organs in menopausal women non-users hormone replacement therapy (HRT). Otolaryngol Pol. 2010;64(1):10-14.

26. Zhai XY, Liu B, Zhang YH, et al. Analysis of BPPV in patients with bone mineral density results [in Chinese]. Lin Chung Er Bi Yan Hou Tou Jing Wai Ke Za Zhi. 2016;30(23):1865-1869.

27. Zhang YM, Yang ZD, Li WX, Shi C, Yu YF. The relationship between the recurrence of benign paroxysmal positional vertigo and the level of bone mineral as well as estrogen in post-menopausal women [in Chinese]. Zhonghua Er Bi Yan Hou Tou Jing Wai Ke Za Zhi. 2017;7; 52(12):881-884. doi:10.3760/cma.issn. 1673-0860.2017.12.001

28. Gu CY, Han WW, Wu YQ, Fan ZY, Chen CJ, Chen HM. Study on bone metabolism in post-menopausal women with idiopathic benign paroxysmal positional vertigo [in Chinese]. Zhonghua Er Bi Yan Hou Tou Jing Wai Ke Za Zhi. 2018;53(2):134-137. doi:10. 3760/cma.issn.16730860.2018.02.010

29. Choi HG, Lee JK, Kong IG, Lim H, Kim SY. Osteoporosis increase the risk of benign paroxysmal positional vertigo: A nested case-control study using a national sample cohort. Eur Arch Otorhinolaryngol. 2019;276(2):335-342. doi:10. 1007/s00405-018-5230-y

30. Liu DH, Kuo CH, Wang CT, et al. Age-related increases in benign paroxysmal positional vertigo are reversed in women taking estrogen replacement therapy: A population-based study in Taiwan. Front Aging Neurosci. 2017;12;9:404. doi:10.3389/fnagi.2017.00404

31. Owada S, Yamamoto M, Suzuki M, Yoshida T, Nomura T. Clinical evaluation of vertigo in menopausal women [in Japanese]. Nihon Jibiinkoka Gakkai Kaiho. 2012;115(5):534-539.

32. Yang L, Xu Y, Zhang Y, Vijayakumar S, Jones SM, Lundberg YYVW. Mechanism underlying the effects of estrogen deficiency on otoconia. J Assoc Res Otolaryngol. 2018;19(4):353-362. 